\title{
Neutrophil extracellular traps
}

\section{Citation}

Demers, Mélanie, and Denisa D. Wagner. 2013. Neutrophil extracellular traps. Oncoimmunology 2(2): e22946.

\section{Published Version}

doi:10.4161/onci.22946

\section{Permanent link}

http://nrs.harvard.edu/urn-3:HUL.InstRepos:10609758

\section{Terms of Use}

This article was downloaded from Harvard University's DASH repository, and is made available under the terms and conditions applicable to Other Posted Material, as set forth at http:// nrs.harvard.edu/urn-3:HUL.InstRepos:dash.current.terms-of-use\#LAA

\section{Share Your Story}

The Harvard community has made this article openly available.

Please share how this access benefits you. Submit a story.

Accessibility 
Neutrophil extracellular traps

\section{A new link to cancer-associated thrombosis and potential implications for tumor progression}

Mélanie Demers and Denisa D. Wagner*

Program in Cellular and Molecular Medicine; Boston Children's Hospital; Boston, MA USA; Department of Pediatrics; Harvard Medical School; Boston, MA USA

Keywords: cancer, NETs, metastasis, neutrophils, thrombosis, tumor progression

Cancers prime neutrophils to release extracellular DNA traps through the systemic release of granulocyte colonystimulating factor (G-CSF). We recently showed that these circulating neutrophil extracellular traps (NETs) promote the establishment of a pro-thrombotic state. The role of NETs in cancer biology and tumor progression may prove much more than an unfortunate side effect of cancer.

Cancers create a systemic environment that predisposes neutrophils to release extracellular DNA traps (NETs). ${ }^{1}$ We identified these traps as new players in cancer-associated thrombosis. Furthermore, their characteristics may provide NETs with a high potential to modulate various facets of tumor biology including metastasis.

It is well known that tumor cells release cytokines in the bloodstream. Granulocyte colony-stimulating factor (G-CSF) is produced by many tumors and is found in the circulation of cancer patients. G-CSF increases the number of neutrophils and induces their activation. Neutrophilia is a frequent finding in cancer patients and is associated with a poor prognosis.

NETs were first identified as a host defense mechanism against pathogens. ${ }^{2}$ Neutrophils engulf pathogens upon contact but-after a strong stimulation, such as during sepsis-the entrapment and killing is mainly mediated through the release of NETs. Following activation by bacteria or cytokines, histone $\mathrm{H} 3$ becomes hypercitrullinated and the neutrophil nucleus undergoes a process of chromatin decondensation that leads to NETosis. ${ }^{3}$ The released DNA is thus associated with citrullinated histone $\mathrm{H} 3$ (H3Cit) but also with enzymes such as myeloperoxidase, cathepsin G and elastase. Our group recently showed that neutrophils, through the generation of NETs, provide a scaffold and a stimulus for platelet adhesion and thrombus formation. ${ }^{4}$ NETs were shown to promote coagulation as well. ${ }^{4,5}$ Since an increased risk of thrombosis is associated with cancer, we hypothesized that tumorinduced neutrophils might have a role in cancer-associated thrombosis.

In a mammary cancer model, we observed neutrophilia that paralleled tumor growth. At the late stage of the disease, when high levels of DNA and H3Cit were found in the plasma, spontaneous thrombosis was observed in the lungs of tumor-bearing mice. ${ }^{1}$ This suggests that, as the disease progresses, NETs are spontaneously formed in the blood and their presence correlates with signs of thrombosis. Are neutrophils from tumor-bearing mice more prone to NETs formation? Indeed, the stimulation of neutrophils isolated from mice with chronic myelogenous leukemia or mice bearing solid mammary or lung carcinomas resulted in a high frequency of NET formation (Fig. 1A). Moreover, the simulation of a minor infection in mammary carcinoma-bearing mice at an early stage of the disease (with a low-dose of lipopolysaccharide) induced both NETosis and a pro-thrombotic state, as reflected by a DNA-dependent reduction in bleeding time. This suggested that both leukemia and solid tumors produce a factor that primes neutrophils to NET formation and predisposes the host to thrombosis. Since G-CSF induces neutrophilia and neutrophil activation and is produced by many tumors, we hypothesized that G-CSF could be such a priming factor. High levels of G-CSF were found in the plasma of tumor-bearing mice. Moreover, we showed that G-CSF treatment of cancer-free mice leads to the hypercitrullination of histone $\mathrm{H} 3$ in neutrophils and hence predisposes them to NETosis. Thus, similar to the mammary carcinoma model, the simulation of a minor infection in G-CSF-treated mice leads to NET release, shortened bleeding time and microthrombi formation in the lungs and kidneys. ${ }^{1}$ Our study identified extracellular chromatin released through NET generation as a key player in cancerassociated thrombosis and unveiled new potential targets in the effort to minimize the incidence of thrombotic events in cancer patients. 


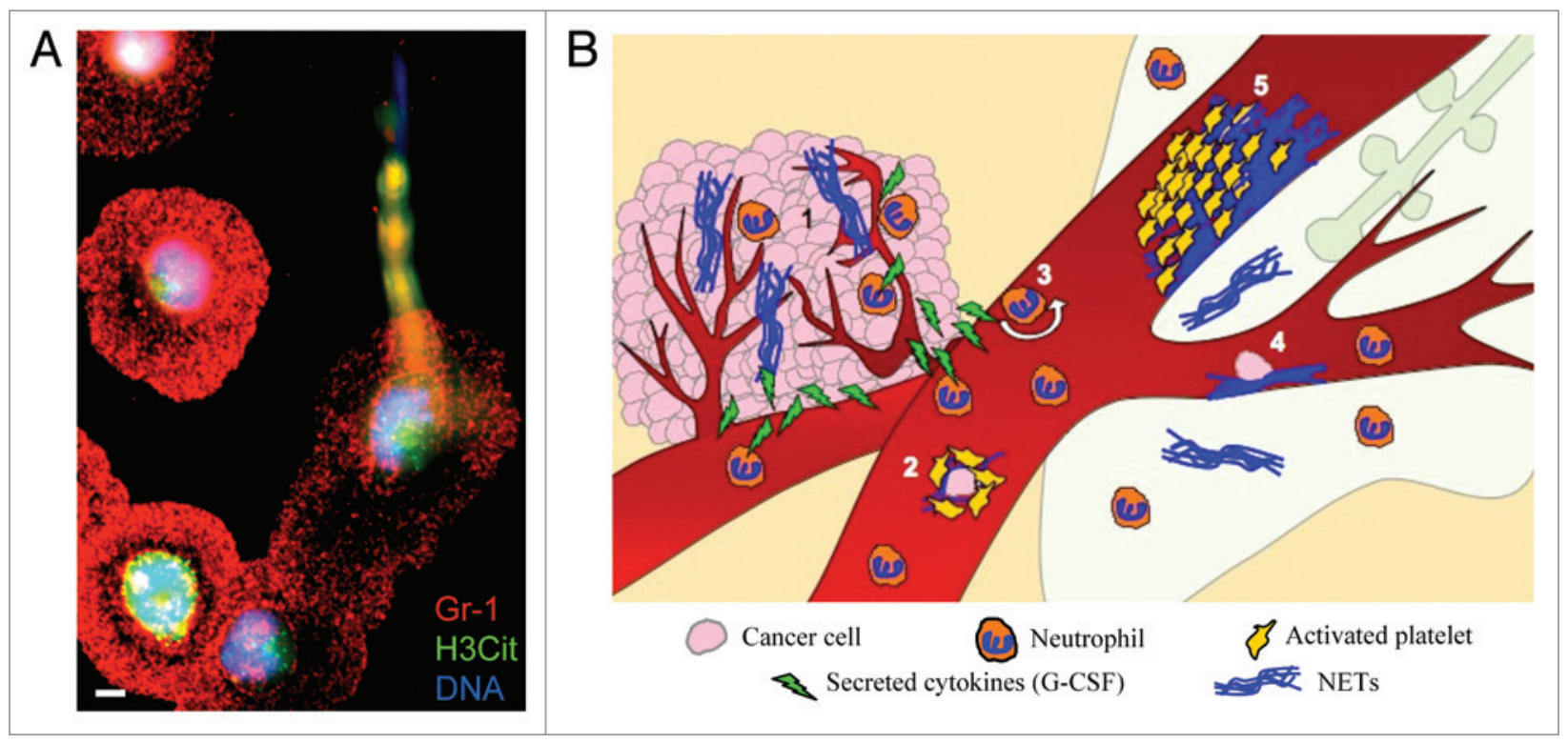

Figure 1. Tumor-induced neutrophils are more sensitive to NET formation and NETs could be implicated in many steps of tumor progression. (A) Representative photograph of a neutrophil in the process of releasing a neutrophil extracellular trap (NET). Immunostaining of neutrophils isolated from tumor-bearing mice following $1 \mathrm{~h}$ activation with calcium ionophore. Significantly more NETs are produced by neutrophils from tumor-bearing mice than from tumor-free mice. Scale bar $=5 \mu \mathrm{m}$. (B) Neutrophils are found in large quantities in the tumor where they can release NETs and affect growth and angiogenesis (1). The generation of NETs in the circulation could protect metastatic cells by adhering to them and recruiting platelets (2). NETs could also activate the endothelium and increase the rolling/adhesion of neutrophils (3) or adhere to the endothelium and favor the arrest of metastatic cells (4), hence allowing their transmigration to a distant organ such as the lung. Finally, the adhesion of a large quantity of NETs to the vasculature may initiate thrombosis by providing a scaffold for platelet adhesion, activation and thrombin generation (5).

Aside from their implication in thrombosis, the formation of NETs in cancer may greatly affect tumor biology (Fig. 1B). Neutrophils have been observed in close association with cancer cells in vivo and within the tumor vasculature, but their exact role in tumor biology is still debated. Tumor-infiltrating neutrophils have been described to have pro- and antitumoral potential. They also secrete cytokines that initiate a positive feedback loop to recruit more neutrophils to the tumor. Intratumoral neutrophils affect the extracellular matrix, promoting tumor growth and invasion, and support angiogenesis. Neutrophils have also been shown to be cytotoxic and induce the apoptotic demise of tumor cells. These opposing phenotypes have been suggested to be related to neutrophil activation state. ${ }^{6}$ Since NETs are released in response to potent activation of neutrophils, it is conceivable that they could be implicated in different steps of tumor progression (Fig. 1B). On one hand, NETs are procoagulant and the thrombin generated as a consequence of NETosis can affect all aspects of cancer. ${ }^{7}$ On the other hand, proteases are an integral part of NETs and may enhance tumor growth/invasion or, together with histones, mediate cytotoxic effects on the microenvironment.

The role of neutrophils in metastasis remains unclear but recent studies have shown that neutrophils directly interact with cancer cells and favor their migration. ${ }^{8}$ The presence of neutrophils was shown to establish a seeding bed for metastatic cancer cells. ${ }^{9}$ However, a toxic effect of tumor-activated neutrophils on cancer cells has also been described. ${ }^{10}$ All these phenomena may implicate NETs (Fig. 1B). In proximity of the vessel wall, ${ }^{4}$ NETs may favor the attachment of the cancer cell to the vessel and support extravasation. Through their proteases and the binding of adhesion molecules such as fibronectin, ${ }^{4}$ NETs may generate a seeding soil and promote tumor cell migration. Finally, NETs could also cover circulating cancer cells with platelets and enhance immune escape.

The finding that tumor-induced neutrophils are more prone to NET formation than their normal counterparts opens up a brand new area of research in cancer biology. The understanding of the function of NETs in tumor progression may lead to new therapies preventing or inducing NETs formation by targeting the innate components of the host immune system. In addition, the neutralization of NETs in cancer patients would presumably reduce the mortality and morbidity resulting from cancer-induced thrombosis.

Disclosure of Potential Conflicts of Interest No potential conflicts of interest were disclosed. 


\section{References}

1. Demers M, Krause DS, Schatzberg D, Martinod K, Voorhees JR, Fuchs TA, et al. Cancers predispose neutrophils to release extracellular DNA traps that contribute to cancer-associated thrombosis. Proc Natl Acad Sci U S A 2012; 109:13076-81; PMID:22826226; http:// dx.doi.org/10.1073/pnas.1200419109.

2. Brinkmann V, Reichard U, Goosmann C, Fauler B, Uhlemann Y, Weiss DS, et al. Neutrophil extracellular traps kill bacteria. Science 2004; 303:1532-5; PMID:15001782; http://dx.doi.org/10.1126/science. 1092385.

3. Li P, Li M, Lindberg MR, Kennett MJ, Xiong N, Wang Y. PAD4 is essential for antibacterial innate immunity mediated by neutrophil extracellular traps. J Exp Med 2010; 207:1853-62; PMID:20733033; http://dx.doi. org/10.1084/jem.20100239.

4. Fuchs TA, Brill A, Duerschmied D, Schatzberg D, Monestier M, Myers DD Jr., et al. Extracellular DNA traps promote thrombosis. Proc Natl Acad Sci U S A 2010; 107:15880-5; PMID:20798043; http://dx.doi. org/10.1073/pnas. 1005743107 .
5. Massberg S, Grahl L, von Bruehl ML, Manukyan D, Pfeiler S, Goosmann C, et al. Reciprocal coupling of coagulation and innate immunity via neutrophil serine proteases. Nat Med 2010; 16:88796; PMID:20676107; http://dx.doi.org/10.1038/ nm. 2184.

6. Gregory AD, Houghton AM. Tumor-associated neutrophils: new targets for cancer therapy. Cancer Res 2011; 71:2411-6; PMID:21427354; http://dx.doi. org/10.1158/0008-5472.CAN-10-2583.

7. Snyder KM, Kessler CM. The pivotal role of thrombin in cancer biology and tumorigenesis. Semin Thromb Hemost 2008; 34:734-41; PMID:19214911; http:// dx.doi.org/10.1055/s-0029-1145255.

8. Huh SJ, Liang S, Sharma A, Dong C, Robertson GP. Transiently entrapped circulating tumor cells interact with neutrophils to facilitate lung metastasis development. Cancer Res 2010; 70:6071-82; PMID:20610626; http://dx.doi.org/10.1158/00085472.CAN-09-4442.
9. Kowanetz M, Wu X, Lee J, Tan M, Hagenbeek T, $\mathrm{Qu}$ X, et al. Granulocyte-colony stimulating factor promotes lung metastasis through mobilization of Ly6G+Ly6C+ granulocytes. Proc Natl Acad Sci U S A 2010; 107:21248-55; PMID:21081700; http://dx.doi. org/10.1073/pnas.1015855107.

10. Granot Z, Henke E, Comen EA, King TA, Norton L, Benezra R. Tumor entrained neutrophils inhibit seeding in the premetastatic lung. Cancer Cell 2011; 20:300-14; PMID:21907922; http://dx.doi. org/10.1016/j.ccr.2011.08.012. 